\title{
Competitive principal of tumor control in radiological clinic
}

\author{
Shoutko AN ${ }^{*}$, Yurkova $\mathrm{LE}^{2}$, Borodulya KS ${ }^{2}$, Ekimova $\mathrm{LP}^{1}$ and Matyurin KS ${ }^{1}$ \\ ${ }^{1}$ Laboratory for Improvement of the Treatment Methods, Russian Research Centre for Radiology and Surgical Technologies, Saint-Petersburg, Russia \\ ${ }^{2}$ Department of Radiology, Russian Research Centre for Radiology and Surgical Technologies, Saint-Petersburg, Russia
}

\begin{abstract}
In order to verify the principle of indirect control a tumor on the base of morphogenic cells distraction from it, the 114 patients with advanced ovarian carcinoma were treated with subtotal half-body (low part) irradiation at low doses (0,1 Gy x 10 for 3 weeks or $3 \mathrm{~Gy}$ x 3 daily), and obtained data were compared with that for 190 patients received conventional local irradiation of the tumor ( $2 \mathrm{~Gy}$ x 23 daily). The surgery and chemotherapy components were equalized in both groups. The 34 $\%$ and $11 \%$ of 5 -years survival was obtained at low dose half body irradiation for primary and relapsed patients in comparison with conventional local radiotherapy ( $7 \%$ and $0 \%)$. It is concluded, that reparation /regeneration processes being provoked artificially in normal tissues of cancer host are capable to compete remotely with tumor for the morphogenic/feeding cells originated from bone marrow and circulating with the blood.
\end{abstract}

\section{Introduction}

Conventional medicine recognizes a selective killing of tumor cells as only way of fighting with cancer. This way has brought some doubtless benefits in the past, but in the last decades the effectiveness of traditional treatment progresses more slowly, than it would be desirable. The life span of mammals at normal conditions and chronic irradiation as well depends on limit of proliferative capacity of bone marrow given at the birth [1]. Despite this, a strong mielodepression follows inevitably palliative chemo- and radiotherapy of cancer. As we argued earlier, the suppression at "therapeutic" range follows by temporary restrictions a morphogenic cells activity inside a tumor [2]. The morphogenic cells (trophocytes / feeding cells) is presented in the blood by hematopoietic stem cells, pro-lymphocytes, angiogenic T-cells and some others [3-5]. There are two ways to restrict the tumor growth's support by them: 1) either to provoke a repopulation stem cells in bone marrow by its injuring with relatively high "hemotoxic" doses of "curative" factor, or 2) to redirect the circulating morphogenic cells from tumor toward a reparation/regeneration of numerous but nonlethal injuries in different normal cells, induced by relatively low doses of "curative" toxicants [2]. In both cases the mechanism of expected benefit has to be not direct but the mediated by rearrangement of the tissues renewing's balance between the cancer and host body. The purpose our presentation is to demonstrate the reliability of described "competitive" approach of cancer therapy at real clinic conditions.

\section{Method}

Since 1995 to 2005 the patients with advanced epithelial ovarian cancer were treated in Russian Research Centre of Radiology and Surgical Technologies of Federal Health Ministry, using 5 MV linear accelerator. The half body (low part) irradiation (HBI) were performed for 114 patients (stage III-56, stage IY-21, relapse 37), and they were compared then with 190 of those (stage III-66, stage IY-25, relapse-99) received conventional local radiotherapy (CLR). All patients have received the surgery before irradiation and chemotherapy after it. The surgery (hysterectomy along with bilateral salpingo-oophorectomy and omentectomy) and standard platinum -based chemotherapy ( $\geq 6$ courses) were identical in HBI and CLR groups. All patients in HBI group were divided before irradiation onto 2 subgroups: primary and relapsed ones. The regime 3Gy x 3daily was used for primary patients, regime $0,1 \mathrm{~Gy}$ x10 for 3 weeks used for relapsed patients.

\section{Result}

Obtained retrospective results (Table 1) prove very clearly the possibility to get best survival without traditional local irradiation of tumor in high, so-called "tumoricydic" total dose 40-50 Gy.

These results are quite comparable with modern data published already by National Cancer Institute, USA, and some others for specific-survival [6,7].

\section{Discussion}

The found distinction between "conventional" and "competitive" therapy may be attributed to the features of a radiation component of both combined schemes. Since 1998, we have been proving indirect mechanism of diminishing the cancer activity by slightly increased natural or artificial background radiation and low dose total/subtotal radiation therapy. In oppose to idea of radiogenic stimulation of anti-cancer immunity $[8,9]$, the mechanism proposed by us bases on the redistribution of circulating morphogenic cells from tumor to exposed normal tissues [10-13], and was statistically tested [14,15]. As a proliferative resource of bone marrow is limited and associated very closely with the life span and the level of lymphopenia [16,17], the HBI with cumulative dose 9 Gy was employed mostly as myelosuppressive

Correspondence to: Shoutko AN, Russian Research Centre of Radiology and Surgical Technologies, Saint-Petersburg, Russian Federation, Russia, E-mail: shoutko@inbox.ru

Received: July 20, 2017; Accepted: August 14, 2017; Published: August 17, 2017 
Table 1. The comparison of the overall 5-years survival after conventional and "competitive" therapies of advanced ovarian carcinoma ( $\mathrm{n}=301$ patients).

\begin{tabular}{|c|c|c|}
\hline $\begin{array}{c}\text { Mode of combined } \\
\text { treatment and } \\
\text { status of cancer }\end{array}$ & $\begin{array}{c}\text { Conventional } \\
\text { Local irradiation } \\
(50 \mathrm{~Gy})\end{array}$ & $\begin{array}{c}\text { Subtotal irradiation } \\
(1 \div 9 \mathrm{~Gy})\end{array}$ \\
\hline \multirow{2}{*}{ Primary } & $6,6 \%$ & $33,8 \%$ \\
\hline \multirow{2}{*}{ Relapse } & $0 \%$ & $\mathrm{p}<0,01$ \\
\hline
\end{tabular}

*cumulative doses are shown; p-value calculated according exact Fisher-test

one. The HBI with cumulative dose $1 \mathrm{~Gy}$ was assumed to be able to divert the circulating morphogenic sells [18] from tumor without diminishing their number. It is obviously, that both regimes cannot provide the tumor growth control by direct killing of malignant cells [19]. They were rather similar with non-selective cytotoxic chemotherapy of cancer, which cannot damage the tumor cells lethally, as the conventional local radiotherapy does. Otherwise, non-selective chemotherapy would be fatal to the organism. Beside this, a myelosuppressive action of modern combined therapy is not the rare, random event, as the $85 \%$ of main anti-cancer drugs are myelodepressants. Hence, the mechanism of any nonselective cytotoxic treatment supposed to be an indirect one also, causing temporary disturbances of cellular reproduction in distant normal tissues [20]. The bone marrow is a main target among them, being the most sensitive/damaged physiological system among those responsible for preservation of life.

\section{Conclusion}

We do not find of any principal objections to continue comprehensive investigation of "competitive" low dose-radiotherapy as an alternative to the nonselective cytotoxic chemotherapy of cancer.

\section{References}

1. Drapeau C (2010) Cracking the stem cell code: demystifying the most dramatic scientific breakthrough of our times. Sutton Hart Press, Portland.

2. Shoutko AN, Ekimova LP (2014) Lymphocytopenia can contribute in common benefit of cytotoxic therapy of cancer. Inter Medical 3: 5-13.

3. Kucia M, Ratajczak J, Ratajczak MZ (2005) Bone marrow as a source of circulating CXCR4+ tissue-committed stem cells. Biol Cell 97: 133-146. [Crossref]

4. Shoutko A, Ekimova L, Mus V, Sokurenko V (2012) Fluctuations of CD34 cells number in blood of cancer patients during final year of life. MHSJ (Acad Publ Platform) 13: 7-13.
5. Shoutko AN, Gerasimova OA, Ekimova LP, Zherebtsov FK, Mus VF, et al. (2016) Long-term activation of circulating liver-committed mononuclear cells after OLT. Jacobs Journal of Regenerative Medicine : 011.

6. Colombo N, Van Gorp T, Parma G, Amant F, Gatta G, et al. (2006) Ovarian cancer. Crit Rev Oncol Hematol 60: 159-179. [Crossref]

7. Wright JD, Chen L, Tergas AI, Patankar S, Burke WM, et al. (2015) Trends in relative survival for ovarian cancer from 1975 to 2011. Obstet Gynecol 125: 1345-1352. [Crossref]

8. Sakamoto K (2004) Radiobiological bases for cancer therapy by total or half-body irradiation. Nonlinearity Biol Toxicol Med 2: 293-316. doi: 10.1080/15401420490900254 [Crossref]

9. Scott BR (2008) Low-dose-radiation stimulated natural chemical and biologica protection against lung cancer. Dose Response 6: 299-318. [Crossref]

10. Shoutko A, Shatinina N (1998) Chronic cancer - could it be? Coherence-Int J of Integrative Medicine 2: 36-40.

11. Shoutko AN Ekimova LP (2014) The impact of middle age on the viability of patients with nonmalignant and malignant diseases. Cancer Research Journal 2: 114-120.

12. Shoutko AN, Ekimova LP (2014) Abnormal tissue proliferation and life span variability in chronically irradiated dogs. Radiat Environ Biophys 53: 65-72. [Crossref]

13. Shoutko AN, Ekimova LP (2017) The effects of tissue regenerative status on hormesis in dogs irradiated during their lifespan. Open Journal of Biophysics 7: 101-115.

14. Shoutko AN, Yurkova LE, Borodulya KS, Ekimova LP (2015) Lymphocytopenia and cytotoxic therapy in patients with advanced ovarian cancer. Cancer Research Journal 3: $47-51$

15. Shoutko AN, Yurkova LE, Borodulya KS, Ekimova LP (2016) Protracted half-body irradiation instead of chemotherapy: life span and lymphocytopenia in relapsed ovarian cancer. International Journal of Tumor Therapy 5: 1-7.

16. Common terminology criteria for adverse events v3.0 (CTCAE) (2003) March 31. Publish Date: 9 August 2006, American National Standards Institute.

17. Rimando J, Campbell J, Kim JH, Tang SC, Kim S (2016) The Pretreatment Neutrophil/ Lymphocyte Ratio Is Associated with All-Cause Mortality in Black and White Patients with Non-metastatic Breast Cancer. Front Oncol 6: 81. [Crossref]

18. Rennert RC, Sorkin M, Garg RK, Gurtner GC (2012) Stem cell recruitment after injury: lessons for regenerative medicine. Regen Med 7: 833-850. [Crossref]

19. Heinzerling JH, Cho J, Choy H (2011) The role of radiotherapy in the treatment of metastatic diseases in Laden D, Welch DR, Paola B, Eds. Cancer metastasis: biologic basis and therapeutics. New York, USA; Cambrige University Press, pp. 612-621.

20. Malhotra V, Perry MC (2003) Classical chemotherapy: mechanisms, toxicities and the therapeutic window. Cancer Biol Ther 2: 2-4.

Copyright: (C2017 Shoutko AN. This is an open-access article distributed under the terms of the Creative Commons Attribution License, which permits unrestricted use, distribution, and reproduction in any medium, provided the original author and source are credited. 